\title{
AIR FORCE MANUFACTURING TECHNOLOGY NDE PROGRAMS SUPPORTING MANUFACTURING AND MAINTENANCE
}

Edward Wheeler

Wright Research and Development Center (WRDC/MTM) Wright-Patterson Air Force Base, $\mathrm{OH}$

\section{ABSTRACT}

Establishment of Nondestructive Evaluation (NDE) techniques and systems is one of the areas that is the responsibility of the Manufacturing Technology Directorate

(WRDC/MTM), Wright Research and Development

Center, ASD. In the past, the majority of the Manufacturing Technology (MANTECH) programs

were directed toward assistance to private industry in their conducting DoD weapons system programs, with spin-offs to commercial production. More recently, increased emphas is has been put on programs to assist the Air Force Logistic Centers (ALCs) in their maintenance and repair of aircraft and engines. This area is known as Repair Technology, or REPTECH, as a part of MANTECH. Airframe and engine oriented programs may contains a modicum of NDE effort but the establishment of NDE systems is accomplished mainly by separate MANTECH programs. R\&D to establish feasibility is conducted by the NDE Branch of the Materials Laboratory.

DISCUSSION

Recent reorganization has established Air Force Manufacturing Technology as a separate directorate of the Wright Research and Development Center (WRDC). Manufacturing technology programs are conducted by the Army, Navy, and Air Force with coordination through the Manufacturing Technology Advisory Group (MTAG) and various other conferences, symposia, and workshops. Establishment of feasibility for NDE programs is achieved by the NDE Branch of the Materials Laboratory, other Government agencies, and industry. NDE programs are also established by the DOD Industrial modernization Incentives Programs (IMIP) (formerly known as Technical

Modernization, or TECH MOD, in the Air Force).

STATEMENT OF PRINCIPLES FOR THE DOD MANTECH PROGRAM.

\section{PROJECT CRITERIA}

Technical Feasibility can be demonstrated

Well defined DoD need with timely delivery

Private industry will not invest at proper time

Anticipated project results are generic

\section{ROI CONSCIOUSNESS}

High leverage ROI

PROGRAM PLANNING

Fully integrated tri-service

IMPLEMENTATION \& TECHNOLOGY TRANSFER

Results readily available to DoD, Industry

EVALUATION

MT program - continuously evaluated

with benefits documented.

MANTECH PROGRAM OBJECTIVES

To significantly improve the productivity and responsiveness of the industrial base by engagina in initiatives which:

1) Insure the economical production of qualitatively superior weapons systems on a timely basis. (overall improvement in manufacturing cost and quality)

2) Reduce DOD material acquisition costs through advanced manufacturing processes, techniques and equipment. (More bang for the buck)

3) Bridge the gap from $R \& D$ to production.

4) Foster greater use of computer technology in all elements of manufacturing.

5) Assure more effective industrial innovation is stimulated by reducing cost and risk.

6) Assure manufacturing processes are safe and meet environmental/energy conservation objectives.

7) Improve export/import balance.

These objectives have a beneficial spin-off to consumer goods. 
REPTECH CRITERIA

1) The project must satisfy a current or expected AFLC depot need with a technology that is not available "off the shelf".

2) Technical feasibility of the project must have been demonstrated in a laboratory environment.

3) The need cannot be satisfied on a timely basis from other known programs.

4) The project must have substantial benefits to AFLC depots.

5) The results of the project will normally have more than one application within the AFLC depot operations. (Generic)

\section{REPTECH OBJECTIVES}

1) Develop and apply technology advances in AFLC depot repair operations which improves readiness, capability and sustainability.

2) Develop and implement appropriate technology to establish, upgrade or modernize manufacture, repair, maintenance and quality control.

3) Introduce new technology into depot repair operations which improves safety and environmental needs.

4) Achieve maximum productivity growth and cost efficiency.

REPTECH programs are reviewed by DOD and industry semi-annually in a REPTECH Conference.

Some current MANTECH programs in WRDC are:

\section{AIRFRAME}

Bonded Structure Repair Center Composite Repair Center

Automated Paint Stripping System

Automated Deriveting System

Parts Replication

\section{ENGINES}

Rotor Stacking System

Integrated Welding and Grinding (I 'AG

Geometric Modeling

Thermal Spray Thickness Gage

Single Crystal Blade Repair

Nickel Boron Plating

OC-ALC Flexible Repair Center

\section{INSPECTION}

Retirement for Cause/NDE

Integrated Blade Inspection System (IBIS)

In-Service Inspection System for Composites (ARIS)

Improved UItrasonic Equipment

(Pulser/Receiver)

$X$-ray Computed Tomographv (CT)

Advanced Transducer Production

Some significant past MANTECH NDE programs are:

\author{
Photogrammetry \\ Eddy Current Disk Inspection \\ Capacitance Hole Probe \\ Automated Dimensional Inspection \\ Inspection for Cracks Under Fasteners
}

\section{RETIREMENT FOR CAUSE/NDE}

The objective of this program is to develop an automated inspection system to detect flaws in gas turbine engine components. The system implements the Air Force Retirement for Cause (RFC) philosphy in which good used engine parts are returned to service, and flawed parts are removed or "retired for cause".

Most high-performance jet engine components have relatively short design lifetimes after which they are scrapped or "retired for life". This is primarily due to the fact that: the materials and fabrication techniques used in making these components have reduced the components' tolerance for small defects; and the small defects are beyond current, reliable Nondestructive Evaluation (NDE) flaw detection techniques.

Currentiy, the decision to retain or retire these components is based on a fracture mechanics statistical judgement... "When 1 out of 1,000 parts could have a fatigue crack likely to grow and cause catastrophic engine failure, a11 1,000 parts are discarded".

Thus, 999 good parts are discarded to insure that one statistically existent defective part has been removed. The RFC concept is based on improving and automating current NDE detection capability so that the one defective part can be reliably identified and removed from service, and the remaining 999 good parts returned to service.

The technical effort on RFC/NDE program is based on previous WRDC and DARPA efforts and incorporates state-of-the-art and proven NDE technologies. The system is modular, utilizes standard communication interfaces, and has extensive computer capability to provide flexibility and expandability. The initial system installed at the San Antonio Air Force Logistics Center (ALC) consists of four eddy current and one ultrasonic 
inspection station and an operator console, all controlled by two VAX 11.780 system computers. These computers perform advanced data processing, system interface, flaw signal analys is and allow for retention of historical flaw data for each engine component inspected. Another eddy current station is on order. One eddy current station will be installed at Oklahoma City ALC in mid-89 with planned number similar to SA-ALC. Estimates by Pratt \& Whitney Aircraft and the Air Force based on the current F-100 engine maintenance rates indicate a potential cost avoidance of nearly $\$ 400$ million for spare parts.

\section{INTEGRATED BLADE INSPECTION SYSTEM}

Automation of key inspection processes for aircraft turbine engine blades and vanes can increase inspection reliability, repeatability, and thoroughness. Automation also reduced quality assurance costs, both in field overhaul activities and in manufacturing. Recognizing these benefits, the U.S. Air Force, Army and Navy have jointly funded the Aircraft Engine Business Group (GE-AEBG) of the General Electric Company to establish the Integrated Blade Inspection System (IBIS), a computer-based, automated system for the precision inspection of individual airfoil parts. The IBIS system is comprised of four automated inspection modules, interconnected through a computerized data management network. Each module is designed to perform a specific type of inspection required during overhaul and/or manufacture of stationary and rotating airfoil parts.

Inspection Methods utilized are:

Visual Inspection

Fluorescent Penetrant Inspection (including penetrant processing)

$X$-Ray for Material Integrity and Internal Geometry Measurements=

Infrared Airflow Measurements (for air-cooled parts)

The Visual Inspection Module (VIM) inspects for airfoil surface defects, such as dents, nicks and scratches. The fluorescent Penetrant Inspection Module (FPIM) inspects for surface flaw indications on parts pre-processed by the Automated Fluorescent Penetrant Pre-Processing Module (AFPPM). The $X$-Ray Inspection Module (XIM) utilizing "Digital Fluoroscopy" and "Computerized Tomography" inspects for internal casting flaws, such as gas porosity, and manufacturing flaws, such as internal hole position and dimensions. The Infrared Inspection Module (IRIM) inspects for internal cooling passage and surface cooling hole blockages. Each module of the IBIS system interfaces to an Information Computer System (ICS), which manages inspection data via an integrated airfoil data base. An important benefit of the system is inspection reliability. Formerly, virtually all part inspections were performed manually and were, consequently, subject to human limitations. Along with improving reliability, this automated system offers greater speed and accuracy.

In summary, the computer-based automatic pre-processing and inspection systems of IBIS offer numerous benefits:

Improved inspection reliability and repeatability

Enhanced inspection thoroughness

Increased inspection productivity Automatic information storage and retrieval

Feedback for process control

Compatibility with ICAM (Integrated

Computer Aided Manufacturing)

"Factory-of-the-Future" concepts

Beyond its immediate application at SA-ALC, IBIS has potential for broad application at other military and commercial overhaul facilities and aircraft engine and airfoil part manufacturing plants.

Significant new technology implemented under the IBIS contracts is already yielding returns in other areas of application. In the future, IBIS can be expanded to include other airfoil part nondestructive inspection techniques and can be modified to permit inspection of other types of aircraft engine parts. In short, the impact of this technology is, indeed, profound.

\section{IN-SERVICE INSPECTION SYSTEM FOR COMPOSITES} (ARIS)

The use of composite structures in military aircraft has grown significantly in recent years, e.g., the $\mathrm{F}-15$ is approximately 2 percent composite bv weight compared to the more recent $A V-8 B$ which is approximately 31 percent by weight. A significant portion of the increased use of composites involves essential aircraft structural components, e.g., wings, stabilators, control surfaces, etc. Consequently, regular inspection of these structures at military installations will become increasingly necessary to help assure adequate structural integrity. To meet these inspection requirements, a practical field inspection capability is needed with attributes such as easy portability, high productivity, user friendliness, good reproducibility, and hardcopy output of the inspection results. The automated real-time inaging system (ARIS) includes these features as well as real-time display of the examination results at the location of the inspector on the aircraft.

ARIS provides automated, simultaneous recordinc of uitrasonic data and search unit position information during a manually scanned inspection of composite and bonded aircraft 
structures with real-time scan coverage and processed data displays. During an examination, the search unit position is continually monitored using an acoustic ranging subsystem. This subsystem transmits time-of-flight information to the centra? processor which in turn calculates position by triangulation calculations. The data and a real-time 16 color display is provided. The real-time display shows part boundaries and indicates where flaws have been detected and where search unit coverage has occurred. This last feature assures complete inspection coverage which is often a concern with marual examinations. Some important features of the ARIS are:

Portability and fast on-site setup Versatility - compatible with manual UT procedures

Pulse echo and through transmission modes $4 \mathrm{ft} \times 4 \mathrm{ft}$ coverage area

Three pixel size selections (.1", .2", $\left..4^{\prime \prime}\right)$

Depth of amplitude display by 16 color scale

Hardcopy documentation (gray scale)

Color recording by "frame grabber" applicable

Electronic templates to define inspection area

Processing and display of comparisons -

present to past inspections

IMPROVED ULTRASONIC EQUIPMENT

(PULSER/RECEIVER)

The assurance that military equipment is capable of achieving its desired performance goal with acceptable cost is an area of major Air Force concern. Nondestructive evaluation (NDE) is a significant contributor to this general area in both production and maintenance. U1trasonic inspection methods are extensively specified and implemented on material and structural components to maintain operational readiness. The objective of this program is low cost, reliable, modular ultrasonic NDE equipment based on the latest advancements in ultrasonic circuitry, transducer design, electronics, fabrication technology, standards, and packaging. The resulting pulser/receive units will be applicable in a wide variety of ultrasonic inspection situations from manual hand-scanning to the more advanced case of computer automated data acquisition, analys is, readout, and storage. Reliable inspection of all metallic and composite airframe and propulsion system materials in a wide range of applications is required. Maintenance inspection costs will be reduced in terms of manpower requirements. Wide usage is expected in USAF depot/field inspection activities, other DOD agencies, and production activities of engine and airframe manufacturers. Greater reliability of, and confidence in, the NDE equipment will extend the useful life of components. Equipment producibility must be at the lowest cost commensurate with performance demands. An additional objective of this program is to establish a capability for manufacturing and marketing the established equipment to provide quantities sufficient for a! 1 anticipated future requirements of the Air Force, other DoD agencies, and commercial users.

Based on Air Force experience and the desires of ultrasonic NDE equipment users, the following goals were established for the Advanced Pulser/Receiver:

\author{
Improved sensitivity \\ Reliability \\ Ease of maintenance \\ Consistent behavior from instrument to \\ instrument \\ Operator appeal - LCD \\ Flexible design - modular \\ User friendliness - menu operation \\ Battery $7 \mathrm{ife}-4 \mathrm{hr}$ min \\ Weight - 30 lbs $\max$
}

The Advanced Pulser/Receiver is substantially improved relative to other portables. A 300 volt square wave pulser gives the instrument penetration power and accurate frequency control to improve test repeatability. Hybridized circuits improve performance while reducing manufacturing costs. Liquid Crystal Disp?ay (LCD)

technology provides a pleasing, easy-to-read operator interface, at little cost to battery life. A Z-80 microprocessor provides intelligence and allows the instrument to store up to 50 test procedures from tech orders.

\section{COMPUTED TOMOGRAPHY}

The objective of this program is to establish X-Ray Computed Tomography (CT) as an eccnomically viable industrial inspection too? for missile and rocket motor hardware/components. Specifically, the goa? of this program is to establish the design, construction, ard operating techniques that will be used for CT systems in a production environment for aerospace nondestructive evaluation (NDE) methodology. Computed Tomography is the reconstruction, by computer of a tomographic plane of an object, also called a slice. It is developed from multiple $x$-ray absorption measurements made around an object's periphery (a scan). The fidelity of the image will depend upon the nature of the $x$-Ray source and the detectors, the numbers and speed of the measurements made, the details of the reconstruction technique (algorithm), the machine characteristics, and the methods of data display and interpretation.

CT was pioneered hy the medical profession and recognized by the Air Force as 
a viable method for inspecting materials. CT offers, for the first time, a quantitative. form of radiography that is married the digital computer with all of its versatility.

By eliminating film or fluorescent screens, CT allows mechanical/electronic inspection of parts and electronics resolution (imaging) of areas of materials undetectable by any film method now available. The fact that $C T$ is digital and not analog allows easy and faithful reproduction of stored images, time and time again because gray levels are represented by numbers easily handled by computers. Computed Tomography has superior large area, low contrast resolutions of images. Standard X-ray films can discern one to two percent contrast differences. The equivalent contrast resolution of quality CT images is 0.1 to $0.2 \%$, an order of magnitude improvement.

Two CT systems were built for the inspection and evaluation of individual components and fully assembled motors. System I (AF/ACTS-I) has the capability for rapid inspection of relatively small (1-M-dia) objects such as tactical rocket motors and components and carbon-carbon integral throat entrances. System II (AF/ACTS-II) is capable of detailed inspection of very large (2.5-M-dia) solid rocket motors and components. These systems are designed to overcome, in a cost effective manner, the current technical limitations to the use of currently available CT systems for industrial inspection application. Both systems provide a sufficient sensitivity and resolution to detect pernicious flaws at a reasonable cost.

\section{ADVANCED ULTRASONIC. NDE TRANSDUCERS}

The Air Force Manufacturing Technology Directorate has recognized the need in this area of technology and has been attempting to fund such a program for more than a decade. In the meantime, the technolngy and the data base have improved rendering this a very timely program to put it all in perspective and make it available to the transducers suppliers. Transducer evaluation programs have shown that there is great variability in the performance of commercially available transducers which are nominally of the same type. This condition still exists despite the fact that rich research literature extending for over 40 years addresses the behavior of ultrasonic transducers. This literature is fully adequate and describes technology which, if applied, will allow reproducible

transducers to be made commercially. Part of the failure to diffuse this knowledge into practice is that the behavior of transducers is perceived by many users and fabricators to be to complex to describe. As a consequence, empirical and artisan methods are still used in transducer design, fabrication, and evaluation. The second important roadblock is the lack of a definitive transducer specification standard and of the tools to measure transducer performance against this standard. Without the specification and evaluation tools, it is impossible for transducer users and manufacturers to effectively communicate requirements or deliver a consistent product. The overall objective of the program is to establish an industry production capability for ultrasonic inspection transducers which are reliable, consistent, and reproducible. It is recognized that the inspection needs of the United States Air Force and other users are widely divergent and cannot be met by a simple set of transducers under vague procurement specifications. The user needs the methodology to better specify transducer performance characteristics and the manufacturer needs to incorporate production techniques which will result in transducers meeting the performance specification.

Specific program objectives are:

Identify the critical parameters which affect performance.

Establish a ceneric specification for transducer procurement.

Establish validated fabrication methods and evaluation tools needed to specify, manufacture, and measure performance of uitrasonic transducers

Disseminate fabrication methods and evaluation tools to the transducer industry and establish user confidence that transducers with reliable performance can be regularly procured.

Vie expect this program to consolidate transducer technology by establishing a uriform system of specifications for ultrasonic NDE transducers.

AIRCRAFT MANUFACTURING QUALITY ASSURANCE USING PHOTOGRAMMETRIC TECHNIQUES

General Dynamics, Fort Worth Division, has completed under contract to the Manufacturing Technology Directorate of the Wright Research and Development Center, a 'program to establish the use of photogrammetric metrology for routine assembly tool alignment verification.

Historically, the aircraft industry has controlled the dimensional integrity of major aircraft component assembly tools by means of component master gages (COMG). Periodically the COMG, which is used in manufacturing the tool, is reinstalled to assure fidelity to the original configuration--a process called Periodic Inspection (PI). In addition to the labcr required for the PI, there are penalties of production downtime and lost productivity. Photogrammetric techniques verify the tool alignment with little or no production downtime and $1 / 4$ to $1 / 10$ the cost of conventional PI. Theodolite techniques are 
used to supplement photography for establishing metrology baselines and for areas requiring greater accuracy.

General Dynamics initiated the comprehensive use of close-range analytical photogrammetry for periodic inspection of F-16 wing and vertical fin assembly tools. This program was conducted in three evaluation phases. The first to establish the utility and cost effectiveness of the photogrammetric technology as applied to complex tools. The second phase was a component assembly coordination study which employed stereo photogrammetric techniques. The final phase evaluated the parameters for use of photogrammetry for very large aircraft tooling.

Photogrammetric PI was implemented on 36 assembly tools, of 8 families, for the $F-16$. These include complex assemblies such as the center fuselage and aft fuselage. It is estimated that the cost avoidance using photogrammetry during the F-16 production program will total $\$ 5$ million. Future cost savings were estimated at $\$ 27$ million for the Air Force and $\$ 10$ million for commercial aircrafts. This program has resulted in a follow-on effort to realign the tools without the use of the COMG and ther to the concept of Gageless Tool Fabrication. This allows tools to be ready for production in 6 months instead of 18 months or more when a master gage is required.

\section{EDDY CURRENT SURFACE. INSPECTION OF DISKS} (EC II)

The EC II Program has established a system capable of eddy current inspection of critical areas on rotating aircraft turbine engine parts, such as disks. The critical inspection areas include bores, rabbet radij, bolt holes, cooling holes, and dovetail slots. Surface connected flaws 0.030 inch long by 0.005 inch deep with a signal-to-noise ration of two are located and reported with high a degree of reliability. The system provides for the automatic scanning, signal processing, decision making, data storage and preparation of print-out reports showing locations of detectable flaws. The manipulator provides six axes of encoded motion and the rotating probe provides the seventh. This allows the system to inspect any geometric surface and report the flaw locations. Additional features of the system include a self-teach mode, automatic re-calibration of the eddy current instrumentation using piece part standards, and a simplified, automatic evaluation routine. The eddy current inspection probes are designed for self-compliance to the part; both universal type and specialized probes are used and are changed manually. The equipment can handle parts up to 250 pounds in weight and 44 inches diameter by 20 inches high at a scan rate of
1-2 inches per second. This system can be expanded to inspect additional selected critical part areas.

Production units have been installed and made operational at San Antonio Air Logistics Center and the Oklahoma City Air Logistics Center. A unit was formally placed into production at the Naval Air Rework Facility at Alameda, CA in July 1984. Since then, three additional units have been installed for the TF-34 engine. This EC II system was a precursor to the Retirement for Cause NDE Sys tem.

\section{INSPECTION FOR CRACKS UNDER FASTENERS (AUTOSCAN-I)}

A major cost item in the life management of Air Force aircraft is the recurring need to conduct inspections to detect cracks under installed fasteners in aircraft structures. The only effective means of detecting cracks on the order of 0.1 inch radial depth or smaller in the first-layer structure has involved removal of the fastener, performance of visual and eddy-current inspections, clean up of the hole, and installation of a new oversize fastener. The removal and replacement of fasteners is not only time consuming and, therefore, expensive, but also can shorten the structural lifetime of the aircraft if the hole is damaged when a fastener is removed or installed.

The Autoscan-I Ultrasonic Flaw Detector was designed to achieve laboratory-quality ultrasonic-flaw-detection capability under field conditions. The instrument uses focused ultrasonic transducers operated in the pulse-echo mode to detector fatigue cracks in the first layer of aircraft structures. The autoscan instrument consists of three major units; a scanner, a pulser/receiver unit, and a circular display unit.

Two focused ultrasonic transducers are used in the instrument. The ultrasound is coupled into the inspection layer by means of a water-filled rubber boot which slides on a mineral-oil uTtrasonic couplant. Two transducers are used in the instrument to provide redundant inspection of an area. One transducer is active when the scanner rotates clockwise about a fastener, and the other transducer is active when the scanner rotates counterclockwise about the fastener.

An eddy-current centering system, indicates to an operator the direction in which to move the instrument in order to center it over a fastener; provides for precise pointing of the ultrasonic beams. The instrument can be centered over flush-mounted, countersunk steel or titanium fasteners in aluminum structures. It can also be centered over holes from which the fasteners have been removed. The precise positioning capability 
of the eddy-current centering system allows the use of focused transducers which provide much higher sensitivity than non-focused transducers.

The Autoscan is capable of inspecting through material thickness up to one inch and for hole diameters of 0.188 to 0.500 inches This system is effective for inspecting for cracks in the second layer of structure in material thicknesses of 0.500 inches for each layer. Low Frequency Eddy-Current has been successfully used in inspecting for cracks in the second layer.

\section{CAPACITANCE HOLE PROBE}

The Capacitance Hole Probe (CHP), now known as a part of the Capacitance Measuring System (CMS), was conceived to reduce the cost of inspecting fatigue critical fastener holes on today's advanced aircraft while still maintaining quality. The system checks the interior characteristics of these holes to assure conformance with engineering specifications. The original CHP was designed to inspect tapered holes for taperlock fasteners but was later applied to straight holes. The CHP is based on the concept of mounting one plate of a capacitor onto a probe the size and shape of the fastener and allowing the hole wall to act as the other plate. Electrical capacitance varies with the distance between the plate segment, or element, and the surface of the hole. This provides a measure of hole size, out of round, and bell-mouthed or barrelling. Poor surface finish, scratches, or rifling in the hole will reduce the capacitance and are measured by developed algorithms. The CHP system uses probe tips with 48 elements in six rows of eight. These are four basic comporents of the CHP system:

The Sensing Device takes the capacitance measurements.

The Electronics Unit converts the measurements into data suitable for processing by the computer.

The Computer, a Hewlett-Packard 9826 , receives and analyzes the data, stores it and notifies the operator of the accept/reject decision.

The Control Unit (hand held) allows the operator to have remote control of the system at the work site and promptly displays inspection results.

The computer pulls from memory the specification requirements and accept/reject criteria for the hole to be inspected. The operator inserts the probe in the hole and presses the trigger switch on the control box. In three seconds the accept, reject, or retest lioht indicates the results. Hole diameters are determined within 0.0002 inch. A print-out graph shows the diameter variation for each of the eight circumferential segments at three levels--top, middle, and bottom--with tolerance limits. Ovality, bellmouthing, or barrelling are readily seen. The CMS may be almost any surface, to check characteristics angularity, or actual dimensional deviation of used with a custom-desianed sensing device for such as degree of curvature, flatness, a curved surface.

\section{AUTOMATED PARTS HANDLING AND DIMENSIONAL} VERIFICATION SYSTEM

The objective of this program was to demonstrate the capability of an off-line multi-station, automated dimensional verification system to contribute to the productivity of a complex production line. The system is capable of processing a wide variety of parts, while maintaining inspection accuracy and data processing integrity. The product of this program is called the Flexible Inspection System (FIS)--a totally automated dimensional inspection facility implemented in the Boeing Aerospace ALCM factory at the Kent Space Center near Seattle. The system demonstrates the interaction of several levels of robotics, automated inspection, and automated material handling coordinated by a central "host" computer system. The establishment implementation and demonstration of this system represents a significant contribution on the part of Quality Assurance toward the Factory of the Future. The integration of robotics, parts handling and dimensional inspection technioues compatible with high productivity manufacturing, resulting in greatly reduced inspection costs, improved production throughout, and established a consistent level of technological sophistication in the modern aerospace factory. The automated coordination link between the automated subsystems of the FIS represents one of the significant accomplishments of the system development. The activities of the FIS are coordinated by a central "host" computer. The inspection equipment includes two coordinate measuring machines--one vertical arm and one horizontal arm--and a multipurpose robotic gage station. This station consisted of a fully automatic ultrascnic thickness gage for ALCM wing skins manipulated by a PUMA robot. The material handiing system consists of a Hyster built, wire guided, RF radio controlled lift truck known as the Storage and Retrieved Vehicle (SRV). Demonstrated FIS performance has proven an actual average reduction in inspection time by $90 \%$ on ALCM parts. The FIS is now being used by Boeing commercial aircraft production inspection. 